\title{
Detection of Trichomoniasis in cattle in Nineveh province
}

\author{
W.A. Al-Obaidii' ${ }^{1}$, Q.T. Al-Obaidi² and S.D. Hasan² \\ ${ }^{1}$ Department of Microbiology, ${ }^{2}$ Department of Internal and preventive medicine, College of Veterinary Medicine, University \\ of Mosul, Mosul, Iraq
}

\begin{tabular}{l} 
Article information \\
\hline Article history: \\
Received March 11, 2020 \\
Accepted April 22, 2020 \\
Available online February 22, 2021 \\
\hline Keywords: \\
Tritrichomonas foetus \\
Cow \\
Clinical status \\
cPCR \\
\\
\hline Correspondence: \\
W.A. Al-Obaidii \\
wasenamjad@yahoo.com
\end{tabular}

\begin{abstract}
The current study was conducted on the detection of Tritrichomonas foetus in vaginal mucus of infected cows using conventional polymerase chain reaction technique (cPCR) in Nineveh province, Iraq. A total of 87 vaginal mucus samples were collected randomly from the vagina of Heifer cows of different ages $(2-4,>4-6,>6$ years old) and stages of pregnancy with different clinical status (early embryonic death, pyometra, abortion and healthy animals once) by washing cow's vagina using artificial insemination pipette, DNA extraction of $T$. foetus was done from vaginal mucus samples, cPCR was attempt using TFR3 and TFR4 primers, Results indicated that 11 cows (12.6\%) were positive for T. foetus. The clinical status of cows demonstrated statistically significant $(\mathrm{P}<0.05)$ a higher percentage of Early Embryonic Death at (6.9\%) compared to pyometra, abortion, and healthy cows. Furthermore, the percentage of $T$. foetus infection was significantly $(\mathrm{P}<0.05)$ elevated among cows ( $>2-4$ years old) at (8\%) compared to ( $>4-6$ years old) and ( $>6$ years old) cows. This study concluded that $T$. foetus infection was an elevated percentage of infection in cows with early embryonic death and in cows (>2-4) years old. This study is the first detected $T$. foetus in cattle in Nineveh province.
\end{abstract}

DOI: 10.33899/ijvs.2020.126790.1380, (C2021, College of Veterinary Medicine, University of Mosul.

This is an open access article under the CC BY 4.0 license (http://creativecommons.org/licenses/by/4.0/).

\section{Introduction}

Bovine trichomoniasis is defining as "a venereal disease caused by Tritrichomonas foetus (T. foetus), that belongs to the class Parabasalia, family Trichomonadidae and phylum Zoomastigina (1). Pereira-Neves et al. (2) define Tritrichomonas foetus as "a single trophozoitic form with a simple lifestyle and the trophozoites, which are spherically shaped, are called 'pseudocyst.' " The parasite can transmit venereal disease from an infected male to cows through coitus or via artificial insemination using contaminated tools (3). The clinical signs in cattle infected with Trichomoniasis can be just mild "vaginitis" or "endometritis," or be as serious as to severe inflammation of the whole reproductive system. Furthermore, other implications include Early Embryonic Death, abortion, and pyometra in pregnant cattle, unable to be pregnant, and decrease calving ratio $(3,4)$. When the clinical signs are not obvious in chronically infected bulls, it is considered as asymptomatic carriers for years, but in acutely infected bulls suffer from lesions and discharge in the genitalia for a short time after infection (5). Numerous diagnostic techniques are used for detecting $T$. foetus with different specificity, and sensitivity such as direct microscopic detection of $T$. foetus in vaginal smears stain by Giemsa stain, but this method is limited when the number of parasites is low. Another method is by inoculating the parasite in different types of culture media., this method takes from two to seven days and does not differentiate between the different types of Tritrichomnas spp. (6). Further, the serological test can be used for diagnosis of the parasite such as mucus agglutination test and ELISA test, but these tests have limited use because of low sensitivity, the specificity of tests, and in bulls do not develop tangible immune responses (7). The polymerase chain reaction is widely used to detect $T$. foetus DNA using different types of primers TF1, TF2, TF3, and TF4. The sensitivity of this PCR 
technique was up to $90 \%$ by using specific primers TFR 3 and TFR4 for $T$. foetus $(8,9)$. Information of $T$. foetus in cattle in Nineveh governorate, Iraq is scarce and therefore, the aims of this study were to detect for the first time, T. foetus in vaginal mucus of infected cows using conventional PCR technique in Nineveh province, Iraq and to ascertain the percentage of $T$. foetus associated with clinical status and different ages of cows.

\section{Materials and methods}

\section{Collection of samples}

This investigation was conducted on 87 cows of different ages (2-4, >4-6, >6 years old), and stages of pregnancy were obtained from different regions in Nineveh province, Iraq. From July 2019 to December 2019, a total of 87 vaginal mucus samples were collected randomly from the vagina of Heifer cows 15 days post-coitus and at different stages of pregnancy by washing the vagina using artificial insemination pipette fitted to a syringe. The pipette was inserted into the vagina, and the syringe repeatedly pressed to flush the vagina with $10 \mathrm{ml}$ Phosphate buffer saline, then aspirated, and the fluid was collected and centrifuged at $3,000 \mathrm{rpm}$, then the pellets were processed as described by Richard et al. (8).

\section{Conventional PCR technique}

Genomic DNA of $T$. foetus was acquired from the cow's vaginal mucus samples using the QIAamp DNA mini kit (Qiagen, Cat No./ID: 51306) and following the product manual. The concentration and purity of the DNA obtained from infected cows were estimated by using Nanophotometer ${ }^{\mathrm{TM}}$ P-Class (IMPLEN, Germany). The concentrations of samples were verified by absorbance (A) at wavelength $260 \mathrm{~nm}$. They were revealed to be between 55 and $92 \mathrm{ng}$, with the purity of $\mathrm{A}_{260} / \mathrm{A}_{280} \mathrm{~nm}$ ratio of 1.8-1.9.

The hypervariable of ITS gene of $T$. foetus from the cow's vaginal mucus samples $(n=87)$ was subjected to amplification as a target in the conventional PCR approach. The oligonucleotide primers were those of Robert et al. (10) and acquired from First BASE Laboratories Sdn. Bhd. Malaysia (Table 1). PCRs were performed, and reaction mixtures (50 ul) contained 5 ul GeneAmp PCR 103 buffer, 2 $\mathrm{U}$ Taq -polymerase, $100 \mathrm{mM}$ of each deoxyribonucleotide, 10 pmol of each primer, and $3 \mathrm{ul}$ of the DNA sample. The mixture was first denatured at $94^{\circ} \mathrm{C}$ for 90 seconds and denatured again by 40 cycles at $94^{\circ} \mathrm{C}$ for 30 seconds, followed by annealing at $67^{\circ} \mathrm{C}$ for 30 seconds and extended at $72^{\circ} \mathrm{C}$ for 90 seconds before concluding with a final 15 minutes extension at $72^{\circ} \mathrm{C}$. The DNA samples after being amplified were put through electrophoresis on $2 \%$ agarose gel stained with Ethidium Bromide to visualize the amplified DNA fragment in the Gel Doc ${ }^{\mathrm{TM}}$ imager (BIO RAD/ USA).

Table 1: Oligonucleotide primers used for amplification of the parasite ITS gene

\begin{tabular}{lll}
\hline Primers & Sequences 5' 3' $^{\prime}$ & Expected size (bp) \\
\hline TFR3 & CGGGTCTTCCTATATGAGACA GAACC & 347 \\
TFR4 & CCTGCCGTTGGATCAGTTTCG TTAA & 3 \\
\hline
\end{tabular}

\section{Statistical analysis}

The difference in the percentages of infection between the various clinical status and ages of cows were assessed by using two-sided Chi-square test in IBM-SPSS statistics version19 program (11).

\section{Results}

In the current study, $T$. foetus was detected in 11 cows with a percentage of $12.6 \%$ in Mosul City, Iraq, by using conventional PCR technique (Table 2). For T. foetus, the positive bands were at nearly 347 bp (Figure 1). Furthermore, the clinical status of cows showed that statistically significant $(\mathrm{P}<0.05)$ elevated percentage of Early Embryonic Death (EED) was 6.9\% compared to pyometra, abortion, and healthy cows (Table 2). The percentage of $T$. foetus infection was significantly $(\mathrm{P}<0.05)$ higher among cows $>2-4$ years old at $8 \%$ compared to cows $>4-6$ years old and $>6$ years old cows (Table 3 ).
Table 2: The percentage of Tritrichomnas foetus associated with the clinical status of cattle using cPCR

\begin{tabular}{lcc}
\hline Clinical status & $\begin{array}{c}\text { Number of } \\
\text { examined cows }\end{array}$ & $\begin{array}{c}\text { Number of } \\
\text { positive cows } \\
(\%)\end{array}$ \\
\hline EED & 23 & $6(6.9)^{\mathrm{a}}$ \\
Pyometra & 19 & $1(1.1)^{\mathrm{b}}$ \\
Abortion & 8 & $3(3.5)^{\mathrm{c}}$ \\
Healthy animals & 37 & $1(1.1)^{\mathrm{b}}$ \\
Total & 87 & $11(12.6)$ \\
\hline Values significantly different $(\mathrm{P}<0.05)$ between cows \\
clinical status are labeled with superscript letters $(\mathrm{a}, \mathrm{b}, \mathrm{c})$.
\end{tabular}




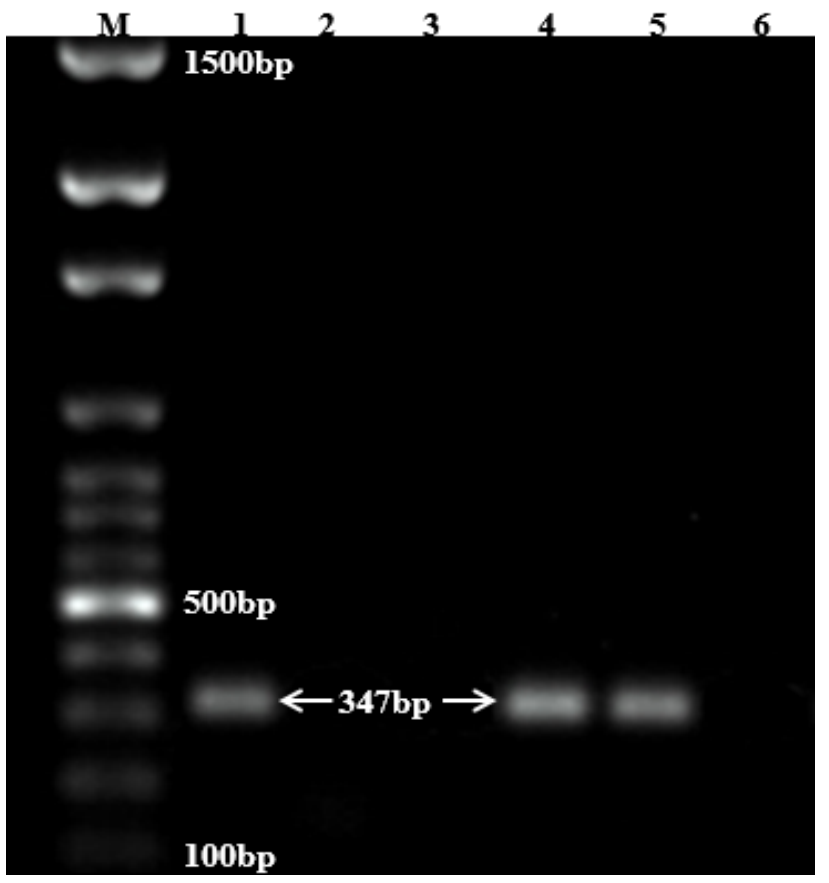

Figure 1: Gel electrophoresis image showing: Lane (M) Exact Mark 100-1500bp DNA ladder; Lanes (2, 3, 6) negative samples to $T$. foetus DNA; Lanes $(1,4,5)$ positive samples to $T$. foetus DNA in approximately band size $347 \mathrm{bp}$.

Table 3: The percentage of Tritrichomnas foetus associated with the ages of cows using cPCR

\begin{tabular}{lcc}
\hline Age of animals & $\begin{array}{c}\text { Number of } \\
\text { examined cows }\end{array}$ & $\begin{array}{c}\text { Number of } \\
\text { positive cows } \\
(\%)\end{array}$ \\
\hline 2-4 years & 39 & $7(8)^{\mathrm{a}}$ \\
$>4$-6 years & 22 & $4(4.6)^{\mathrm{b}}$ \\
$>$ 6 years & 26 & $0(0)^{\mathrm{c}}$ \\
\hline Total & 87 & $11(12.6)$ \\
\hline
\end{tabular}

Values significantly different $(\mathrm{P}<0.05)$ between cows of different ages are labeled with superscript letters $(\mathrm{a}, \mathrm{b}, \mathrm{c})$.

\section{Discussion}

This current investigation reported the percentage of $T$. foetus infection in cows in Nineveh province was $12.6 \%$, which is higher compared to previous studies in Iraq. Baqer (12) indicated that the percentage of Trichomoniasis in slaughtered bulls was $2 \%$ in Basrah province using microscopic examination of slide smear stained with Giemsa stain. Studies undertaken in other countries reported different percentages of $T$. foetus infection in Sheridan cattle, USA reported $2.9 \%$ of infection in cattle employing PCR technique (13); in Canada it was 6\% using PCR (14); in California it was $15.8 \%$ using culture media (15); in Nevada it ranged between 26.7 and $44.1 \%$ (16); In Australia 122 of
$689(17.7 \%)$ cattle were found to be positively infected with T. foetus (17), and in Costa Rica it was $6.7 \%$ in cows over 4 years old (18). The percentage of $T$. foetus infection differs from country to country and between regions within the same country, which might be due to different management practices, how sensitive and specific the diagnostic tests are, as well as the presence and the efficacy of the control programs (19).

The clinical status of infected cows demonstrated that statistically significant elevated rate of Early Embryonic Death (EED) was $6.9 \%$ compared to pyometra, abortion, and healthy cows, findings which are in agreement with Joanna et al. (20) how observed that the clinical signs of cattle infection with $T$. foetus rang from moderate vaginitis or metritis to severe inflammation of genitalia. Furthermore, in times of pregnancy, it results in early embryonic death, abortion, and pyometra. Infertility and abortion in infected cows occur because the parasite is able to infect the mucosal membrane of the genital tract which causes adherent $T$. foetus cells and release cysteine protease (CP30) that creates cytopathic effects in oviduct cells, epithelial cells of the vagina and uterus, with resultant apoptosis, and the cysteine protease is able to cleave $\mathrm{IgG} 2$ and evade the immune response of the host (21).

The findings of this investigation indicate that the percentage of $T$. foetus infection is higher among cows $>2-4$ years old, this finding corresponding with that of BonDurant, (22) who found that the majority of cows and young bulls (younger than 3 years old) could possibly achieve spontaneous clearance of the infection. Further, cows typically clear their infection in 3 months or less and gain a brief period of immunity to $T$. foetus no less than a year and sometimes as long as three years. However, it is inconsistent with the findings of Yao, (23) who recorded a high percentage of infection in heifers in comparison with cows because it is possible for cows to retain immunity against infection for as long as three years after being infected while cows regain from infection, in general, possess immunity against infection for one to three years but there can be variations between animals. In order to control $T$. foetus infection in a flock, bulls under 3-4 years of age are used instead of animals older than 3-4 years (17). In this study, conventional PCR was used to detect $T$. foetus because of the high specificity and sensitivity of this technique for the detection of the parasite (9).

\section{Conclusions}

T. foetus infection was first detected in cows in Nineveh province, with a higher percentage of infection in cows with early embryonic death and in cows >2-4 years old. Therefore, $T$. foetus infection must be addressed through early diagnosis and preventive treatments against the parasite, as well as using specific vaccines against it. 


\section{Acknowledgment}

The authors wish to thank the College of Veterinary Medicine/ University of Mosul for financially supporting this work, laboratory of the veterinary teaching hospital, for their support and the animal's owners for their cooperation.

\section{Conflict of interest}

Author declare no conflict of interests of the manuscript.

\section{References}

1. Paul R. Bovine trichomoniasis: Veterinary clinics of north America. Food Anim Pract. 1986;2(2):277-286. DOI: 10.1016/S0749$\underline{0720(15) 31237-8}$

2. Pereira NA, Campero CM, Martínez A, Benchimol M. Identification of Tritrichomonas foetus pseudocysts in fresh preputial secretion samples from bulls. Vet Parasitol. 2011;10;175(1-2):1-8. DOI: 10.1016/j.vetpar.2010.10.007

3. OIE Terrestrial Manual. Trichomonosis. 2018:1-12. [available here]

4. Agnew DW, Corbeil LB, Munson LA. Pregnant mouse model for bovine Tritrichomonas foetus infection. Vet Pathol. 2008;45(6):849864. DOI: $10.1354 / \mathrm{vp} .45-6-849$

5. Lady CC, Milena JI, Rubiela CS, Adriana PP, Humberto GM, Moisés AS, Milton JR. Determination of presence of Tritrichomonas foetus in uterine lavages from cows with reproductive problems. Rev Bras Parasitol Vet. 2012;21(3):201-205. DOI: 10.1590/S198429612012000300005

6. Ginter S, Hairgrove TB, Schroeder M, Conley R, Bounpheng MA. Improvements in Tritrichomonas foetus molecular testing. J Vet Diagn Invest. 2018;30(4):603-608. DOI: 10.1177/1040638718767943

7. Jovanka M, Voyich RA, Donald EB. Antibody responses of cattle immunized with the Tf190 adhesin of Tritrichomonas foetus. Clin Diag Lab Immunol. 2001;8(6):1120-1125. DOI: 10.1128/CDLI.8.6.11201125.2001

8. Richard SJ, Felleisen NL, Bruno G. Detection of Tritrichomonas foetus by PCR and DNA enzyme immunoassay based on rRNA gene unit sequences. Clin Microbiol Rev. 1998;36(2):513-519. [available here]

9. Mukhufhi M, Irons PC, Michel A, Peta F. Evaluation of aPCR test for the diagnosis of Tritrichomonas foetus infection inbulls: Effects of sample collection method, storage and transportmedium on the test. Theriogenol. 2003;60:1269-1278. DOI: 10.1016/s0093691x(03)00138-9

10. Robert HB, Carlos MC, Mark LA, Karen AH. Detection of Tritrichomonas foetus by polymerase chain reaction in cultured isolates cervicovaginal mucus, and formalin-fixed tissues from infected heifers and fetuses. J Vet Diagn Invest. 2003,15:579-584. DOI: 10.1177/104063870301500613

11. Leech NL, Barrett KC, Morgan GA. SPSS for intermediate statistics: Use and Interpretation. USA: Lawrence Erlbaum Asso; 2007. 1-97 p.

12. Baqer JH. Detection of bovine trichomoniasis of bulls in Basrah slaughterhouse. Bas J Vet Res. 201312(1):98-103. [available here]

13. Douglas N, Merle EO, Gilbert AS. An improved polymerase chain reaction assay for the detection of Tritrichomonas foetus in cattle. CanVet J. 2002;43(3):213-216. [available here]

14. Bon Durant RH, Anderson ML, Blanchard P, Hird D, Danaye-Elmi C, Palmer C, Sischo W M, Suther D, Utterback W, Weigler BJ. Prevalence of trichomoniasis among California beef herds. J Am Vet Med Assoc. 1990;196:1590-1593. [available here]

15. Riley DE, Wagner B, Polley L, Krieger JN. PCR-based study of conserved and variable DNA sequences of Tritrichomonas foetus isolates from Saskatchewan, Canada J Clin Microbiol. 1995;33:13081313. [available here]
16. Kvasnicka WG, Taylor RE, Huang D, Hanks R, Tronsta A, Bosomworth $\mathrm{H}$. Investigations of the incidence of bovine trichomoniasis in nevada and of the efficacy of immunizing cattle with vaccines containing Tritrichomnas foetus. Theriogenol. 1989;31(5):963-971. [available here]

17. Dennett DP, Reece RL, Barasa JO, Johnson RH. Observations in the incidence and distribution of serotypes of Tritrichomonas foetus in beef cattle in north-eastern Australia. Aust Vet J. 1974;50:427-431. [available here]

18. Perez E, Conrad PA, Hird D, Ortuno A, Chacon J, Bon Durant R, Noordhuizen J. Prevalence and risk factors for Tritrichomonas foetus infection in cattle in northeastern Costa Rica. Prev Vet Med. 1992;14:155-165. DOI: 10.1016/0167-5877(92)90013-6

19. Yao C. Diagnosis of Tritrichomonas foetus-infected bulls, an ultimate approach to eradicate bovine trichomoniasis in US cattle. J Med Microbiol. 2013;62(1):1-9. DOI: 10.1099/jmm.0.047365-0

20. Joanna D, Jacek K, Maciej K, Jacek S, Jolanta Z, Tomasz C. Tritrichomonas foetus as a causative agent of tritrichomonosis in different animal hosts. J Vet Res. 2019;63(4):533-541. DOI: 10.2478/jvetres-2019-0072

21. Talbot JA, Nielsen K, Corbeil LB. Cleavage of reproductive secretions by extracellular proteinases of Tritrichomonas foetus. Can J Microbiol. 1991;37:384-390 [available here]

22. Bon Durant RH. Pathogenesis, diagnosis, and management of trichomoniasis in cattle. Vet Clin North Am Food Anim Pract. 1997;13:345-361. [available here]

23. Yao C. Tritrichomonas foetus infections in female beef cattle with abortion in Wyoming, USA. JMM. 2015;2(2):1-5. DOI: $\underline{10.1099 / j m m c r .0 .000028}$
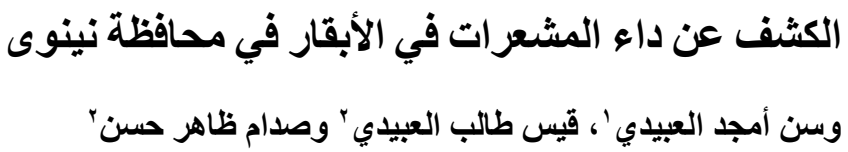

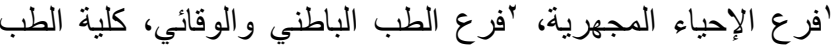

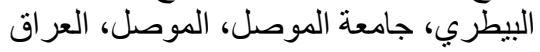

الخلاصة

أجريت هذه الدر اسة لغرض الكثف عن طفيلي المشعر ات في مخاط

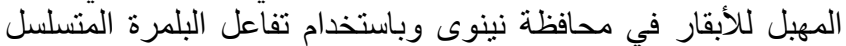

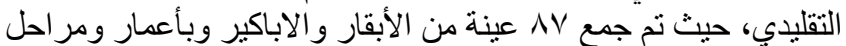

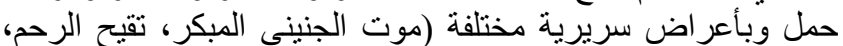
إجهاض) فضلا عن السليمة منها تم غسل المهبل للأبقار باستخدام

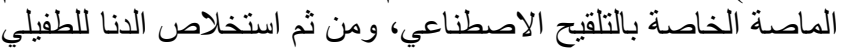

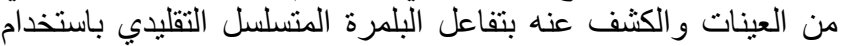

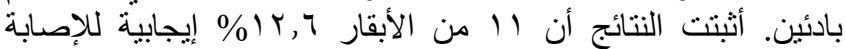

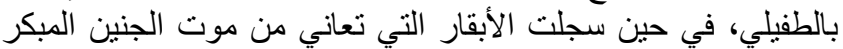

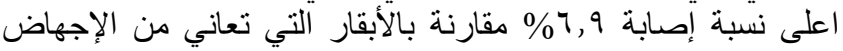

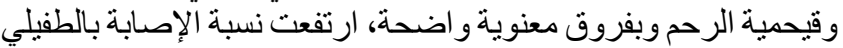

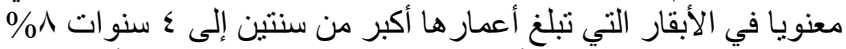

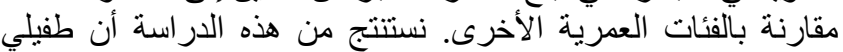

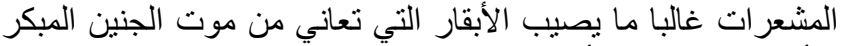

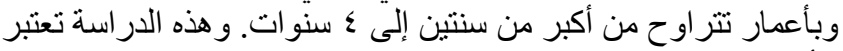

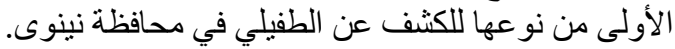

